\title{
O Jubileu Magistral de Reynaldo Porchat $\left({ }^{\star}\right)$
}

\author{
Waldemar Ferreira
}

Os que, senão apenas uma, mais de uma vez ultrapassam os vinte e cinco anos de vida, ao sentirem maior a caminhada feita do que a fazer, comprazem-se, nos seus momentos de repouso espiritual, como nos grandes momentos, em recompor, pela imaginação, que é criadora, os panoramas, que a memoria, que é perdularia, conserva na sua propria retina e distribui como dadiva consoladora. Recordar é reviver e, de certo modo, dar-se cada um a si mesmo, como aos que o cercam, o contingente do passado, em que se alicerçam as esperanças, que são as promessas do presente, e que o futuro, sempre caprichoso, nem sempre realiza.

Estamos, neste instante, reunidos neste recinto augusto e majestoso, que é novo, mas nos parece sempre velho para comemorar acontecimento ocorrido, precisamente, ha cinquenta anos. Nomeado, após concurso brilhantissimo, em que se consagrou, pelos votos dos notaveis catedraticos de então, digno da investidura; nomeado, por efeito de tal concurso e por decreto de 18 de outubro de 1897, lente substituto da primeira sessão do curso de bacharelado desta Faculdade de Direito - empossou-se no cargo, aos 23 do mesmo mês e ano, o bacharel Reynaldo Porchat, a quem,

(*) Discurso proferido a 23 de outubro de 1948, pelo cinquentenário professoral do eminente mestre, nas solenidades comemorativas realizadas pela Universidade de São Paulo na Faculdade de Direito. 
na forma regimental, no mesmo ato se colou o grau de doutor em direito.

Bacharelado em 1891, ele fez parte de turma egregia, que tanto se destacara nas lutas academicas, e em que, desde logo, se ergueram três tribunos: Marinho dE Andrade, cuja palavra o destino logo emudeceu; Pedro MoAcir, que foi, na Republica, senão o eco, o porta-voz do grande orador dos pampas - Silveira Martins; e Reynaldo Porchat, que dentro de poucos minutos se ouvirá, e pela primeira vez, neste salão, ha poucos dias inaugurado. Foram os três lideres da que, ao tempo, se chamou — de "questão academica", que se encerrou com o afastamento da catedra do grande professor de direito civil - o conselheiro Justino Gonçallves DE ANDRADE, que tantas gerações tiveram como mestre, e dos maiores, e tanto contribuiu para oengrandecimento da cultura juridica brasileira. Português de origem, mas filho desta casa, em que se formou, toda sua vida foi dedicada ao ensino juridico e nisso residia o seu maior orgulho. Desentendeu-se o velho professor com os seus discipulos e do conflito resultou o seu afastamento, o que não impediu continuasse ele a merecer a estima, que jamais se desvaneceu, de quantos por este velho mosteiro transitaram. Deu aquela turma ao ensino juridico contingente dos mais notaveis, como talvez nenhuma outra, pois que dela ascenderam ao magisterio Astolfo Rezende e ANtonio Passos de Miranda Junior, na Faculdade Nacional de Direito da Universidade do Rio de Janeiro; Estevam DE Magalháes Pinto e Rodrigo Bretas de Andrade, na Faculdade de Direito de Belo Horizonte, da Universidade de Minas Gerais; Leonardo Macedonia, Tiburcio de Azevedo e Normelio Rosa, na Faculdade de Direito de Porto Alegre, da Universidade do Rio Grande do Sul; Gabriel José Rodrigues de Rezende, José Mendes, Candido Nazianzeno Nogueira da Motta, José Ulpiano Pinto de Sousa e Reynaldo Porchat, na Faculdade de Direito da Universidade de São Paulo.

Estes dois professores emeritos da Faculdade de Direito. de São Paulo empossaram-se no mesmo ano, José Ulpiano 
em fevereiro e REynatdo Porchat na data cujo cinquentena-rio hoje passa. Civilista eminentissimo, JosÉ UlpIANo sempre se mostrou retraído e arredio, em perene esquivança, receoso de tornar publica a sua admiravel cultura juridica. Posto em disponibilidade em 1925, aquiesceu em representar São Paulo na Assembléia Constituinte de 1934. Findo: o seu mandato, recolheu-se á sua vida quieta e serena, cujo silencioso recato neste momento me proponho romper, enviando-lhe, desta tribuna, as manifestações de maior apreço e da estima sempre afetuosa dos professores e dos alunos. da Faculdade de Direito, a que nos honramos de pertencer.

Terminado o meu curso de bacharelado em ciencias e letras, no Ginasio Nogueira da Gama, que o grande educa-dor Lamartine Delamare dirigia em Jacareí, vim iniciar o meu curso juridico em 1904. Mal tinha comecado o seculo e eu andava ali pelos dezoito anos, o seculo e eu cheio de expectativas e de inquietações. Aquele não prenunciara o que viria ser o seu espirito, formado ao calor das guerras, de que resultariam as duas grandes armas arrazadoras. - a aeronave e a bomba atomica; e eu - pobre de mim! - nenhuma veleidade poderia alimentar porque não pas-sava de calouro e calouro, "in illo tempore", como nos tem-pos angustiosos que passam, não tem direito de ser outra. coisa, senão e apenas calouro, o que já não é pouco.

Logo nos primeiros dias aconteceu fato de suma importancia. As materias do primeiro ano eram duas - filosofia do direito e direito romano. Prelecionavam-nas, diariamente, menos às quintas-feiras, PEdro Lessa e ReynalDo Porchat, aquele na celebre sala n. 2; e este na sala dos tumulos, que era a sala n. 1. Dirigia-se Pedro Lessa para sua sala a fim de fazer o seu cavaco inaugural, quando, á porta, se estabeleceu conflito entre veteranos e calouros. O lente não se sentiu satisfeito. Retirou-se e formulou, na secretaria, perante Julio MaIA, que respondia pelo expediente, o seu protesto. Avisado, o diretor - que era JoÃo MonteIro - compareceu. Inteirado do ocorrido, apresentou-se no alto da escada de marmore do átrio do antigo 
edificio, a do lado esquerdo, que levava á sala da diretoria, no primeiro andar. O seu vulto varonil, firme e ereto como o de Joaquim Nabuco, chamou a atenção das gerais. Reunimo-nos, comprimindo-nos. $\mathrm{E}$ ele começou a discursar, fazendo-nos a mais severa reprimenda. Mas JoÃo Monteiro era grande orador. O tribuno, em dado momento, suplantou o diretor; e o discurso eloquentissimo, acabou debaixo das mais ruidosas aclamações.

Depois disso, as aulas iniciaram-se e correram normalmente, como sempre acontece. A bonança sucede à tempestade. $\mathrm{E}$ os dois insignes catedraticos, pois Reynaldo Porchat se empossara da catedra no ano anterior, entraram a expor as suas respectivas disciplinas. Eram duas grandes figuras, distintas e notaveis, que se emparelhavam como professores verdadeiramente modelares. PEDro LESsA, mineiro do Serro, primeiro como substituto, depois como catedratico, exercia o magisterio desde 1888. Era mais que quarentão. Senhor de si mesmo, ciente e consciente de sua autoridade, que era insuperavel, iniciara o curso explicando, antes de entrar no programa, psicologia e logica. Eu me senti maravilhado. O meu curso ginasiano de logica, não tinha sido eficiente; e por dois motivos. Um, o de não ter sido precedido pelo de psicologia, e era o principal; e outro o de que, em vez de compendio elementar, a materia entrou a ser exposta pelo grande tratado de AleXANDRE BAIN, que exigia esforço imenso de principiantes. Pedro Lessa, espontaneamente, se propôs preencher a lacuna e fê-lo magistralmente. Quando começou a desenvolver o seu notavel programa, o criador do ensino de filosofia do direito no Brasil tinha já, como bom semeador, preparado o terreno para o receptaculo das sementes e a colheita dos frutos. Que grande professor foi aquele! Pedro Lessa não era orador, mas expositor de grandes recursos. A despeito de certa monotonia locucional, empolgava pela clareza, pelo metodo e pela profundeza do ensinamento. As palavras, emitidas cadenciadamente, à moda serrena, eram claras, porque serviam a espirito lucido de sabio. Não é claro quem o queira, senão apenas quem conheça a mate- 


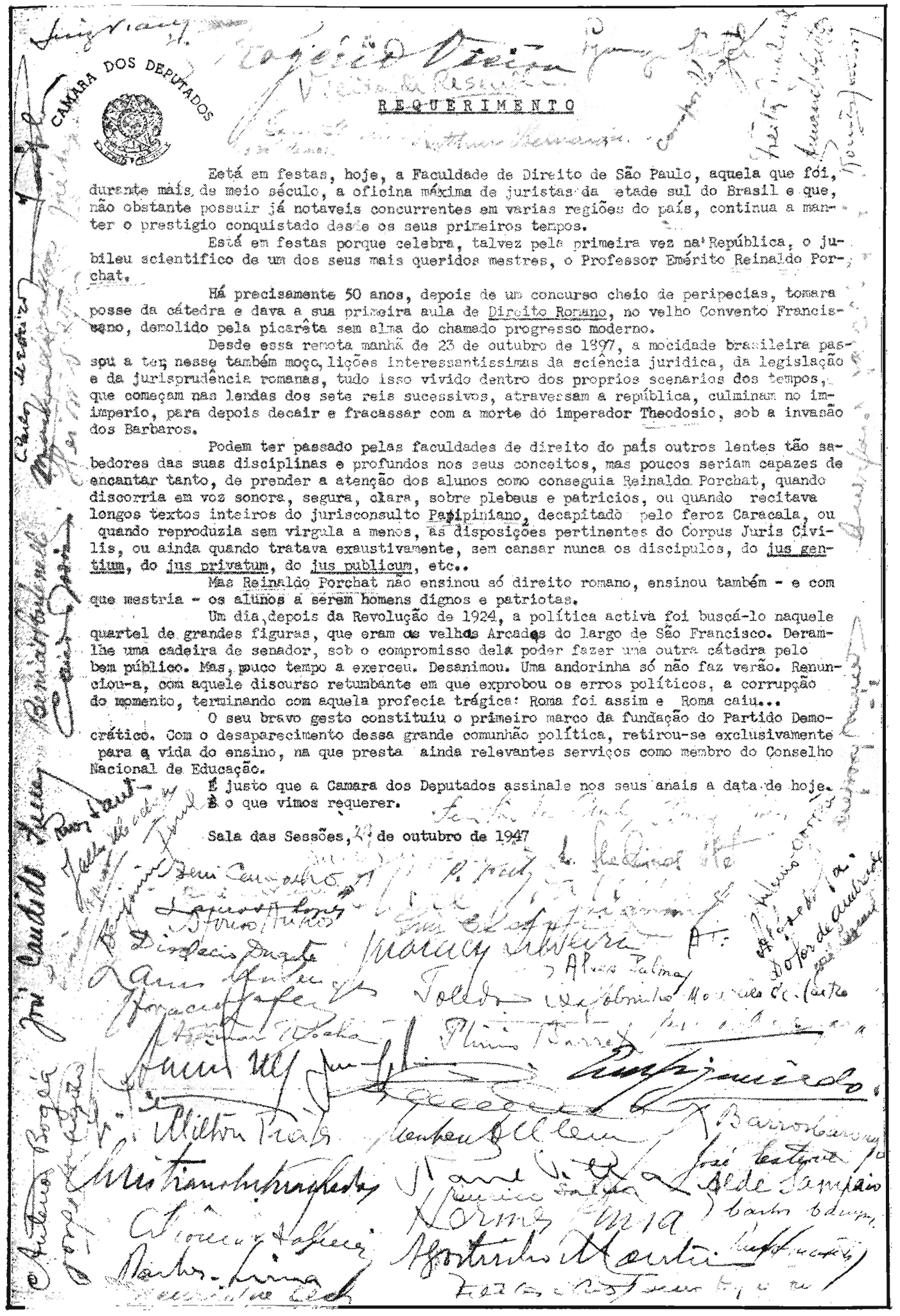


ría, de que trate, no geral e no particular, nos principios gerais e na sua aplicação aos casos particulares.

Reynaldo Porchat ia completar os seus trinta e cinco anos. Deu-se o evento em 23 de maio de 1904. Guardo dessa data lembrança imperecivel. Residia ele em velho casarão terreo da rua Marechal Deodoro, que fôra a antiga rua do Imperador e começava na praça, que JoÃo Mendes veio a chamar-se, e fôra da Assembléia. Terminava no largo da Sé, pouco adiante da rua da Caixa Dagua, que depois adotou o nome do grande poeta Baráo de ParanagiaCABA. O casarão possuia uma janela baixa, seguida de porta larga e atrio vasto, a que se sucediam outras quatro janelas, bem em frente à rua Senador FerJó. Terminada a aula do dia, o bedel Frederico Batista de Sousa nos anunciara que Reynaldo Porchat receberia, á noite, em sua casa, os seus alunos do primeiro ano. A noticia, nas arcadas, ecoou satisfatoriamente; e o convite foi aceito. Reunidos no largo de São Francisco, dirigimo-nos para a casa do professor de direito romano. Fui honrado por meus companheiros de turma com a incumbencia de saudar o mestre eminentissimo. Coube-me por sorte, não somente pronunciar o meu primeiro discurso academico, como dirigir-vos, mestre diletissimo, a minha primeira saudação. A vossa resposta, em que vos referistes ao livro de LYTTON sobre os ultimos dias de Pompéia, para aludir ao soldado romano, que, firme no seu posto se mantinha, enquanto a multidão fugia das lavas do Vesuvio, como simbolo da autoridade e do direito, que os cataclismas podem abafar, não, porém, extinguir, calou fundo, porque exprimia a inteireza do vosso espirito e do vosso carater, como professor de direito e guião da mocidade.

O direito romano, dizieis, é um dos grandes monumentos que a humanidade tem produzido e circunda de gloria o povo que o organizou. Sua influencia, e repetieis conceitos de Ihering, não se restringe às instituições que adotamos dos romanos; nosso pensamento, nosso metodo, nossa forma de intuição, toda a nossa educação juridica, tornou- 
se romana, se é possivel chamar de romana a uma coisa de verdade universal, que os romanos tiveram o merito de desenvolver até à sua mais alta prefeição. Tendo de pô-lo, a tal monumento, diante da inteligencia e, sobretudo, em face da intuição dos moços, não agistes como iconoclasta. Os monumentos somente se compreendem e exercem seu papel, tanto de marcos de fastos historicos, como de instrumentos de educação das gerações que os contemplam, nos cenarios em que originalmente se ergueram, e se mantêm. Transporte-se o Coliseu ou o arco de Tito, que em Roma se encontram nos seus ambientes propicios, para a cidade maravilhosa de São Sebastião do Rio de Janeiro, e aqueles monumentos não terão maior significado do que o obelisco de Lougsor na praça da Concordia, de Paris, e cujos hieroglifos não revelam, nem para os parisienses, nem para os viajores sedentos de emoções novas, os altos feitos de RamsÉs, que em Tébas foi rei glorioso e verdadeiramente imortal. Para ensinar direito romano a estudantes brasileiros, tinheis, necessariamente, sr. Reynaldo PoRchat, de reconstituir-lhes Roma e pô-la, através dos acontecimentos sociais e politicos, tanto quanto economicos, a criar o seu direito, expressão maxima da cultura juridica latina.

Com esse proposito, antecedieis vosso curso de parte preliminar, tratando da importancia e da influencia do direito romano sobre a legislação dos povos cultos, e, principalmente, sobre o direito civil patrio. Ainda hoje se debate se tal disciplina deve figurar no programa dos cursos juridicos. Meu entendimento sempre foi pela afirmativa pelo bem que ele me fez no formar-se minha consciencia juridica, desde que explicado como me foi pelo metodo que adotastes. Batida a primeira estaca, seguia-se resumido historico do direito romano, que me parece indispensavel, e fazieis com incomparavel mestría e singular eloquencia. Reconstituindo os eventos historicos, salientando o espirito do povo romano em todos os momentos de sua trajetoria economica, social e politica, revivieis os fatos juridicos e os monumentos legislativos que se iam formando, tudo em 
linhas gerais, mas incisivas e fecundas. Não ereis o ledor frio de textos latinos, mas o vivificador da doutrina, que neles se encerrava. De tal arte, quando, dentro em pouco, atingieis o ponto da decadencia do estudo do direito e de sua ossificação, para a posteridade, nos grandes codigos em que ele hoje se contẹ́m, até ao de Justiniano, mais não havieis feito do que expôr o espirito do direito romano e o processo por que, adormecendo nos codigos, reviveu para a eternidade. Mas não era só isso. Ensinando direito antigo para moços de tempos modernos, desconhecedores do direito nacional, antes da entrada no exame dos institutos do direito romano, pertinentes aos capitulos das pessoas e das coisas, do direito da familia e do sucessorio, dos direitos pessoais e dos direitos reais, conceituaveis o direito, quer o romano, quer o atual, nos seus preceitos fundamentais, nas suas divisões e subdivisões, classificando as materias do direito privado e do direito publico, dizendo da justiça, da aequitas e da jurisprudencia; da lei e de sua interpretação, abrogação e derrogação, iniciando a teoria moderna do direito adquirido e da retroatividade, bem como do erro e da ignorancia do direito.

Depois disso é que se entrava na parte especial da disciplina; e o principal já se encontrava prelecionado, proveitosa e utilmente.

Nem sempre consentia o tempo que esgotasseis o programa; mas a parte dele, que era possivel a professor explicar, frequentando a catedra com inexcedivel assiduidade, era bem explicada e bem aprendida.

Aqui estou - decorrido tanto tempo! - a fazer a apologia do vosso ensinamento, meu querido mestre; e para apontar aos moços, que me ouvem, um padrão de mestre de Direito. Eu vos saudo, pelo que fizestes, em nome não só da Faculdade de Direito, mas de toda a Universidade de S. Paulo, que aqui está reunida para festejar o vosso jubileu magistral!

Mas nem somente fostes professor de Direito, sr. REYNALdo Porchat. Advogado dos mais brilhantes do foro 
paulistano, nele conquistastes vitorias magnificas, precisamente porque sois jurisconsulto de grande estirpe.

Um dia, a política, que quase sempre desfalcava as nossas catedras, em busca de figuras que fossem dignas do Senado, que então existia no organismo do Estado, veio buscar-vos. Fostes e lá permanecestes até quando verificastes que era inutil a vossa presença e, mais do que ela, o vosso labor. Nessa encruzilhada do vosso destino, renunciastes à vossa curul senatorial. Foi acontecimento inedito na vida politica de S. Paulo. Homens de todas as idades e de todas as profissões acorreram à vossa casa grande da rua das Palmeiras, entregando-vos caloroso manifesto de solidariedade; e tive eu a fortuna de ser o interprete dos sentimentos de todo o povo paulista; foi a segunda oração que dirigi ao insigne homem do Direito e da lei; e isso em janeiro de 1926.

Entre outras, proferi estas palavras:

"O nosso país está envolvido em trevas de um longo estado de sitio, que atingirá todo o quatrienio. Desconfiancas. Suspeitas. Suspensão das garantias constitucionais. Crise financeira e economica. Crise moral e politica. D país varado, de sul a norte, por uma onda revolucionaria, que ainda se não acabou. Mas acima de tudo isso sente-se, em estado latente, por sobre a nebulosa, almas em anseios, espiritos em estado de evocação, corações palpitando pelo Brasil, nossa terra e terra dos nossos filhos!

E o futro, é o amanhã que está a madrugar, à espera do cantar dos galos matutinos, anunciando o alvorecer. Na vossa oração de despedida ao Senado, fizestes um apelo aos moços para que se não descuidassem do Brasil e não o deixassem morrer de morte moral. Os moços, naturalmente, saberão cumprir o seu dever e ei-los a se congregarem em todo o país para, numa arrancada para a frente, levarem o Brasil aos ombros, pelo futuro a dentro. Eles saberão batalhar com nobreza, desprendimento e galhardia, pela renascença brasileira".

E conclui : 
"Mas existem em S. Paulo os velhos paulistas, homens de muito pulso e de muito coração, que prepararam, com a nitida visão dos tempos, este espantoso progresso material do nosso Estado, quase uma nação dentro da Nação. Para eles, sr. Reynaldo Porchat, deveis tambem dirigir o vosso apelo, em nome de todos nós. Que os velhos paulistas, que o pessimismo ainda não desnorteou, dirijam os moços e os aconselhem e com eles se confraternizem e possamos todos trabalhar pelo engrandecimento do Brasil!"

Aquele apelo não se perdeu no vacuo. Os moços reuniram-se aos velhos e entre os velhos houve um que tomou a dianteira e alçou a bandeira do Partido Democratico o conselheiro Antonio Prado. Ao lado do grande paulista, fostes, sr. Reynaldo Porchit, um dos grandes paladinos do voto secreto e da reestruturação politica, que somente se poderia obter, ademais, com o voto proporcional, que ensejaria a formação dos partidos politicos, que, por falta de um e de outro, nunca antes se puderam constituir e viver. Mas aquelas palavras, que datam de vinte e um anos, ainda são oportunas e atuais, sr. REYnalddo PoRchat. No momento em que a situação politica de S. Paulo se encontra abastardada e o grande Estado decaído, por obra dos proprios paulistas, no seu prestigio na politica nacional, demais não é, professor eminentissimo, que reitereis o vosso apelo, a fim de salvar S. Paulo da humilhação e da ignominia! Apelai para os paulistas para que não amortalhem o Estado das Bandeiras nos lençóis dos intimos do Catete, em vassalagem sem par!

A vossa aposentadoria vos afastou da catedra, a que destes o brilho inconfundivel da vossa cultura romanistica, em 1925. Depois de 1930, retornastes ao velho mosteiro, como seu diretor, e, interrompendo para isso o exercicio do cargo, em que o voto da Faculdade de Direito sempre foi continuo e persistente, por via de reeleições sucessivas, em conferir-vos para representa-la, a principio no Conselh; Superior do Ensino, depois no Departamento Nacional do Ensino e, ainda agora, no Conselho Nacional de Educação, a que presidis! 
Ali vos achais na brecha, a trabalhar pela causa educacional. Que lidador espantoso! Os anos caem sobre vossos ombros, mas continuais na luta incessante e edificadora!

Outro interregno se deu no exercicio daquela função publica. Foi em 1934. Fundada pelo saudoso Armando DE Salles OliveIra, a Universidade de S. Paulo - neste momento reunida sob a presidencia de seu magnifico reitor ereis, sem duvida, o homem indicado para instala-la e po-la em funcionamento. Investido no titulo e no cargo de Primeiro Reitor da Universidade de S. Paulo, as responsabilidades de seus primeiros passos sobre vós cairam; mas, com o vosso alto senso e incomparavel descortino, ela estava fadada a vencer e a tornar-se o monumento de cultura, de educação e de ensino que é o justo orgulho de S. Paulo e dos paulistas!

Por todos esses titulos, justifica-se a homenagem que, por esta minha oração - que é a terceira que vos dirijo a Universidade de S. Paulo, por iniciativa da Faculdade de Direito, vem agora prestar ao antigo professor de Direito romano e ao seu primeiro reitor, comemorando o seu jubileu professoral.

Levantai, sem orgulho, mas desvanecidamente, sr. REYNALDO PoRchat, as mãos limpas e benfazejas para o céu, pois que, como poucos, tendes a suprema ventura de ver afirmada pelos vossos antigos discipulos e pelos vossos contemporaneos, que sois digno dos seus aplausos e da sua admiração profunda e sincera! 